\title{
Nitric oxide in preeclampsia and its association with thyroid hormone levels - A case control study
}

\author{
Nineetha Muraleedharan ${ }^{1, *}$, M. Saboora Beegum ${ }^{2}$, Jessy S. J. ${ }^{3}$ \\ ${ }^{1}$ Assistant Professor, ${ }^{2}$ Professor \& HOD, ${ }^{3}$ Associate Professor, Dept. of Biochemistry, ${ }^{1}$ SUT Academy of Medical Sciences, \\ Trivandrum, Kerala, ${ }^{2,3}$ Government Medical College, Trivandrum, Kerala, India
}

*Corresponding Author:

Email: mnineetha@gmail.com

Received: $25^{\text {th }}$ October, 2017

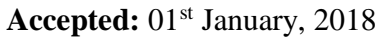

\begin{abstract}
Introduction: Preeclampsia is a common disease of vascular dysfunction in pregnancy. Previous studies have suggested that nitric oxide, a vasodilator decreases in preeclampsia. This could lead to a decrease in thyroid capillary flow as suggested by few studies, thereby causing a decrease in thyroid hormones. Present study aims to investigate nitric oxide in preeclampsia and also seeks to find any correlation between nitric oxide and thyroid profile in preeclampsia.

Materials and Methods: In this Case-Control study, 40 preeclampsia subjects as cases and 40 pregnant women as controls at 3038 weeks of gestation were involved. $5 \mathrm{ml}$ of venous blood was collected to assay serum nitric oxide using chemical method (Griess assay) and thyroid profile (T3, T4, TSH, FT3 and FT4) using ELISA.

Analysis and Results: Mean, median, standard deviation for quantitative variables was compared by student t test. Percentage values were compared using Chisquare test. ANOVA tests and Post Hoc analysis was done. Nitric Oxide was significantly decreased in preeclampsia $(20.5 \pm 3.03 \mu \mathrm{mol} / \mathrm{L})$ than in normal pregnant $(26.25 \pm 5.09 \mu \mathrm{mol} / \mathrm{L})$. It was significantly decreased even in mild preeclampsia $(\mathrm{p}<0.001)$. There was a decrease in thyroid hormones and increase in TSH in preeclampsia. There was a correlation between decreased nitric oxide levels and decreased T3 and FT4 levels, but not with the remaining thyroid hormones. Conclusion: Preeclampsia is associated with a significant decrease in serum nitric oxide and thyroid hormone levels. In this study, we found correlation between decreased thyroid hormones (T3 and fT4) and nitric oxide levels, which was not significant. However preeclamptic women should be screened for hypothyroidism both during pregnancy and in post-natal period.
\end{abstract}

Keywords: Preeclampsia, Nitric Oxide, Thyroid profile, TSH, FT3, FT4.

\section{Introduction}

Preeclampsia is pregnancy specific disease defined as the onset of hypertension and significant proteinuria in a previously healthy woman on or after $20^{\text {th }}$ week of gestation. It is a common cause of morbidity and mortality, occurring in $2-8 \%$ of pregnancies worldwide. ${ }^{1}$ In India, prevalence of preeclampsia is reported to be $5.4 \%{ }^{2}$ The risk factors for preeclampsia are nulliparity, multifetal gestation, Diabetes Mellitus, vascular and connective tissue disease, genetic factors etc. ${ }^{1}$

The pathophysiology is characterized by placental hypoxia, excess oxidative stress and endothelial dysfunction. Various studies report an increase in antiangiogenic factors like sFLT-1 and soluble endoglin which in turn decreases the activation of endothelial nitric-oxide, which is a vasodilator of utero-placental vessels. ${ }^{1,3}$ It is proposed that deficient nitric oxide may contribute to preeclampsia pathophysiology. ${ }^{4}$

Nitric oxide is also found to regulate secretion of thyroid hormones by affecting the regional blood flow in thyroid capillaries. ${ }^{5}$ Ides et al suggested that eNOS expression in thyroid follicular cells suggest a possible role for Nitric oxide in thyrocyte function and growth. ${ }^{6}$ Various studies have reported decreased ${ }^{7}$ unchanged $^{8}$ or increased ${ }^{9}$ nitric oxide levels in preeclampsia. Also there is a need to find out any relation between thyroid status and nitric oxide levels in preeclampsia, as there are no previous studies based on this.

Hence, the present study is aimed to test the nitric oxide levels in preeclampsia and also to find out its relation with the thyroid hormone status in preeclampsia. In future, the use of nitric oxide donors may prevent complications of preeclampsia, including hypothyroidism.

\section{Materials and Methods}

In this case control study wherein the cases include pregnant women with preeclampsia, defined as the occurrence of hypertension $(\mathrm{BP} \geq 140 / 90 \mathrm{mmHg}$ ) and significant proteinuria ( $\geq 300 \mathrm{mg} /$ day) in a previously healthy pregnant women on or after $20^{\text {th }}$ week of gestation. ${ }^{10}$ The controls include normal pregnant women without preeclampsia. The total sample size is 80 , where 40 are cases and 40 are controls. This study was done at Department of Biochemistry and the Department of Obstetrics and Gynaecology of Government Medical College, Thiruvananthapuram during a period of 1 year from January 2012 to January 2013.

Cases included all diagnosed cases of preeclampsia between 30-38 weeks of gestation. Equal number of healthy pregnant women in $3^{\text {rd }}$ trimester attending the antenatal clinic during the study period constituted the 
control group. History of thyroid disease, congenitally malformed baby, hypertension, renal disease, any metabolic disorder, or any intake of medication that might affect thyroid function was excluded from the study. This study was conducted after getting the clearance from institutional ethical committee.

The details of study subjects were recorded in proforma after getting their informed consent. Additionally details in proforma are of symptoms suggesting severe preeclampsia-headache with visual disturbances, epigastric pain etc was noted. Abnormal lab results like those of liver or renal function tests etc were also recorded. All the chemicals and reagents used in the study are of analytical grade. $5 \mathrm{ml}$ of venous blood was collected from study subjects, centrifuged and serum was stored at $-20^{\circ} \mathrm{c}$ until use. Serum nitric oxide was measured by Griess reaction chemical method. ${ }^{10}$ The values were measured in JASCO UV spectrophotometer. Thyroid profile (FT3, FT4, T3, T4 and TSH) was measured using ELISA (Enzyme Linked Immunosorbent Assay) and read in ELx 800MS, ERBA MICROSCAN ELISA machine.

Expected ranges for thyroid hormones ${ }^{12}$ are $\mathbf{T 3}=0.8$ $-2 \mathrm{ng} / \mathrm{mL}, \mathbf{T 4}=4.4-12.8 \mu \mathrm{g} / \mathrm{dL}, \mathbf{T S H}=0.5-5 \mathrm{mIU} / \mathrm{L}$ (normal females) and 0.13-3.5 mIU/L (in $3^{\text {rd }}$ trimester of pregnancy) ${ }^{[19]}, \mathbf{F T 3}=1.4-4.2 \mathrm{pg} / \mathrm{ml}, \mathbf{F T 4}=0.8-2$ $\mathrm{ng} / \mathrm{dL}$.

Expected range of values for Nitric Oxide $=\mathbf{1 0 . 1}$ - 65.6 $\boldsymbol{\mu m o l} / \mathbf{L}^{13}$

\section{Analysis and Results}

Statistical analysis was performed using SPSS version 16 (2007, Chicago, SpssInc). The mean and standard deviation for quantitative variables was calculated for the study population. Difference in percentage values were compared using Chisquare test or Fischer's T test. Difference in the group means of quantitative variables was compared by student $t$ test. ANOVA tests were done to compare study parameters between severe preeclampsia, mild preeclampsia and normal controls. Pearson's correlation coefficient was obtained to study correlation between thyroid hormonal values and albumin in cases. A p value of less than or equal to 0.05 is considered to be statistically significant.

When we compared means of different variables between cases and controls (Table 1), the mean age of preeclampsia patients were $24.98 \pm 2.8$ and that of normal pregnant were $24.5 \pm 3$ years. Mean gestational age of cases is $34.5 \pm 2.6$ and that of controls is $35.5 \pm 2.5$ weeks. There is no significant difference in age and gestational age between cases and controls. On comparing difference in parity, 26 out of 40 cases (preeclampsia patients) or $65 \%$ were primigravida and 23 out of 40 controls (normal pregnant) or $57.5 \%$ were primigravida. Remaining are multigravida. This difference in parity was not significant $(\mathrm{p}=0.491)$ according to Chisquare test. Hence cases and control groups were comparable.

Table 1: Comparison of means of general characteristics and different variables

\begin{tabular}{|c|c|c|c|}
\hline \multicolumn{2}{|c|}{ Variable } & \multicolumn{2}{|c|}{ Mean \pm SD* } \\
\hline & & Cases $(n=40)$ & Controls $(n=40)$ \\
\hline \multicolumn{2}{|c|}{ Age in Years ${ }^{\dagger}$} & $24.98(2.8)$ & $24.55(3)$ \\
\hline \multicolumn{2}{|c|}{ Gestational age in wks } & $34.50(2.6)$ & $35.50(2.5)$ \\
\hline \multirow[t]{2}{*}{ Parity } & Primi ${ }^{*}$ & $26(65)$ & $23(57.5)$ \\
\hline & multi & $14(35)$ & $17(42.5)$ \\
\hline \multicolumn{2}{|c|}{ S. Nitrite $(\mu \mathrm{mol} / \mathrm{L})^{\dagger}$} & $20.50(3.03)$ & $26.25(5.09)$ \\
\hline
\end{tabular}

$* \mathrm{SD}$ - standard deviation, $\dagger$ continues variables expressed in Mean $\pm \mathrm{SD}$,

$\$$ Categorical variable expressed in frequency (\%).

The mean nitrite levels among cases was $20.50 \pm$ 3.03 and in controls was $26.25 \pm 5.09 \mu \mathrm{mol} / \mathrm{L}$ (Table 1). The median nitrite among cases is 20 and that of controls is $26 \mu \mathrm{mol} / \mathrm{L}$. The mean and median nitrite of cases was found to be lower than controls. Students $t$ test was done and $\mathrm{p}$ value is $<0.05$. Hence the difference in mean is statistically significant. Cases (40) were divided into severe (18) and mild (22) preeclampsia according to diagnostic criteria for severe preeclampsia ${ }^{14,15}$ and were compared with controls (40) in terms of serum nitrite (Table 2).

The mean serum nitrite was 21,20 and $26 \mu \mathrm{IU} / \mathrm{L}$ and median nitrite was 20,20 and $26 \mu \mathrm{IU} / \mathrm{L}$ for severe, mild preeclampsia and controls respectively. ANOVA showed a $p<0.01$; hence the difference in nitrite values are significant. There was no significant difference in the nitrite values between severe and mild cases $(\mathrm{p}=0.407)$. The nitrite values of severe and mild cases were lower than controls and the difference was statistically significant $(\mathrm{p}<0.001)$ (Table 2$)$.

Table 2: Comparison of serum nitrite between 3 groups

\begin{tabular}{|l|c|c|c|}
\hline \multirow{2}{*}{ S. Nitrite $(\boldsymbol{\mu I U} / \mathbf{L})$} & \multicolumn{2}{|c|}{ Pre eclampsia } & \multirow{2}{*}{ Control } \\
\cline { 2 - 3 } & Severe & Mild & \\
\hline N & 18 & 22 & 40 \\
\hline Mean & 21.11 & 20.00 & 26.25 \\
\hline Median & 20.00 & 20.00 & 26.00 \\
\hline SD & 3.29 & 2.78 & 5.09 \\
\hline Min & 16.00 & 14.00 & 18.00 \\
\hline Max & 28.00 & 26.00 & 40.00 \\
\hline F & \multicolumn{3}{|c|}{19.132} \\
\hline
\end{tabular}




\begin{tabular}{|l|c|c|c|}
\cline { 2 - 4 } $\mathrm{p}$ & \multicolumn{3}{|c|}{$<0.001$} \\
\hline $\begin{array}{l}\text { Post Hoc analysis } \\
\text { (Paired } \\
\text { comparison) }\end{array}$ & Severe & Mild & $\mathrm{p}=0.407$ \\
\cline { 2 - 4 } & Severe & Control & $\mathrm{P}<0.001$ \\
\cline { 2 - 4 } & Mild & control & $\mathrm{P}<0.001$ \\
\hline
\end{tabular}

The mean T3,T4,fT3 and fT4 of cases significantly lower than controls (Table 3), while mean TSH was significantly higher, thus indicating the development of hypothyroidism in preeclampsia.

Table 3: Thyroid function tests among cases and controls $^{12}$

\begin{tabular}{|c|c|c|}
\hline \multirow[t]{2}{*}{ Variable } & \multicolumn{2}{|c|}{ Mean \pm SD $^{\dagger}$} \\
\hline & Cases $(n=40)$ & Controls $(n=40)$ \\
\hline T3 (ng/mL) & $1.28(0.36)$ & $1.62(0.21)$ \\
\hline $\mathrm{T} 4(\mu \mathrm{g} / \mathrm{dL})$ & $11.59(2.59)$ & $13.63(1.92)$ \\
\hline TSH (mIU/L) & $3.76(1.55)$ & $2.30(0.94)$ \\
\hline FT3 (pg/mL) & $2.12(0.55)$ & $2.43(0.47)$ \\
\hline FT4 (ng/dL) & $1.16(0.24)$ & $1.33(0.27)$ \\
\hline
\end{tabular}

$\uparrow$ SD - standard deviation

To test whether this has any relation with the lower nitric oxide levels in preeclampsia, we did a correlation study between TFT and nitric oxide levels in cases (Table 4). There is a positive correlation only between T3 and FT4 with serum nitrite among the 40 cases. However the correlations between TFT and serum nitrite are not statistically significant (Table 4, Graph 1, Graph 2).

Table 4: Correlation of serum nitrite with thyroid function tests in preeclampsia

\begin{tabular}{|l|c|c|c|}
\hline S. Nitrite & $\mathbf{N}$ & $\mathbf{r}$ & $\mathbf{p}$ \\
\hline T3 & 40 & .172 & .288 \\
\hline T4 & 40 & -.015 & .927 \\
\hline TSH & 40 & .204 & .207 \\
\hline FT3 & 40 & -.067 & .680 \\
\hline FT4 & 40 & .142 & .384 \\
\hline
\end{tabular}

Graph 1: Positive correlation between fT4 and serum nitrite

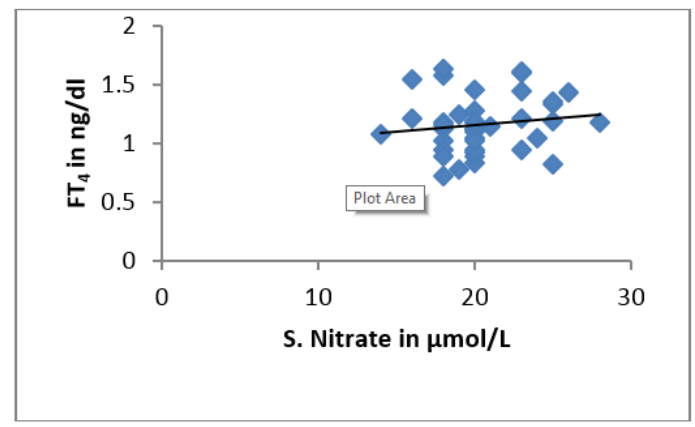

Graph 2: Positive correlation betweenT3 and serum nitrite

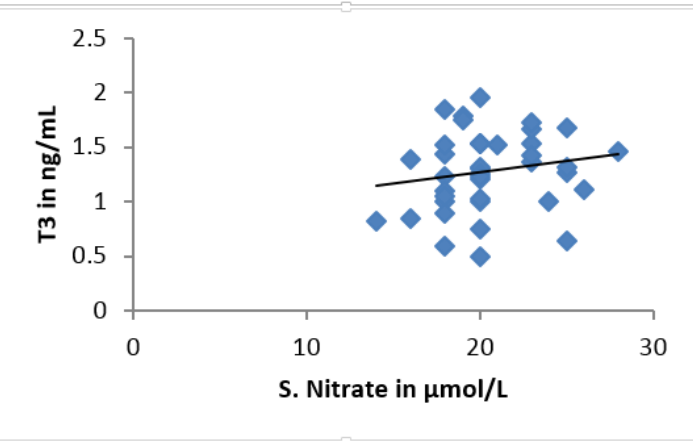

\section{Discussion}

Preeclampsia is now considered to be a vascular dysfunction in pregnancy, where there is an imbalance between vasoconstrictor and vasodilator agents. Many studies suggest a decrease in nitric-oxide, which is a vasodilator of utero-placental vessels. In our study also we got significantly lower serum nitrite values in preeclampsia compared to normal pregnant. However all the cases and controls have serum nitrite in the expected range itself $(10.1$ and $65.6 \mu \mathrm{mol} / \mathrm{L})$.

Suchanda et $\mathrm{al}^{7}$ studied 30 normal and 30 preeclampsia cases in their 3rd trimester of pregnancy and found significant decrease in nitrite levels in cases. Valeria et al ${ }^{16}$ also found significantly decreased nitrite in preeclampsia. A Korean study by Jong Weon Cheoi ${ }^{17}$ et al., on 19 preeclamptic women found that nitrite production increases in normal pregnancy and decreases in preeclampsia. Ahmet et $\mathrm{al}^{18}$ found that decreased NO levels are closely associated with preeclampsia related endothelial dysfunction. This is supported by Maul et al. ${ }^{19}$ However some studies like that of Hudicek et $\mathrm{al}^{20}$ have reported an increase in nitric oxide in preeclampsia. Lyall et al, ${ }^{21}$ Silver et al, ${ }^{22}$ Boccardoet $\mathrm{al}^{23}$ have reported no significant differences in nitric oxide from women with and without preeclampsia.

Forty cases of preeclamptics were divided into 18 severe and 22 mild preeclampsia groups based on severity assessment criteria. ${ }^{14,15}$ Both preeclampsia groups had significantly lower mean nitrite than the normal pregnant women. The difference in nitrite between severe and mild was not significant.

The preeclampsia group was found to have significantly decreased thyroid function. ${ }^{12}$ It is hypothesised that decrease in nitric oxide may reduce capillary flow in thyroid vessels, leading to hypothyroidism. To test this, a correlation test was done between serum nitrite and thyroid parameters (T3, T4, TSH, fT3, and fT4). Serum nitrite shows positive correlation with T3 and FT4, but there is no statistical significance for the relation of nitrite with thyroid function tests. 
Mc Allister et $\mathrm{al}^{24}$ showed that synthesis of vascular NO was decreased in hypothyroidism in rats. Rodriguez et $\mathrm{al}^{25}$ studied NO production in 10 newborns diagnosed with congenital hypothyroidism and found undetectable plasma NO levels in them.

\section{Conclusion}

Serum nitric oxide values are decreased significantly in preeclampsia. This is prominent even in mild preeclampsia. Since nitric oxide is a vasodilator, its decrease may lead to reduced utero-placental flow. Correlation studies assessed the relation between nitric oxide levels and thyroid hormones in preeclampsia. Only T3 and FT4 decreased with a decrease in nitric oxide levels. This was not statistically significant. Hence, decrease in nitric oxide does not seem to influence thyroid status in preeclampsia. In future, the use of nitric oxide donors may prevent complications of preeclampsia, including hypothyroidism. Large scale population studies are needed to substantiate this.

\section{Acknowledgements}

We are extremely thankful to Dr C Nirmala, who was the HOD of the department of Obstetrics and Gynaecology during the study period. We also thank Dr. Kumari Jayageetha PB, Associate Professor in Statistics and Demography, Department of Community Medicine, Medical College, Trivandrum and $\mathrm{Mr}$ Jayakumar P who helped us with the statistical work of this study.

There are no conflicts of interest in our study.

\section{References}

1. Elosha Eiland, Chike Nzerue, Marquetta Faulkner. Preeclampsia 2012. Journal of Pregnancy 2012;ID 586578.

2. Manjusha sajith, Vandana nimbargi, Amit modi, Ronak sumariya, Atmaram pawar. Incidence of pregnancy induced hypertension and prescription pattern of antihypertensive drugs in pregnancy. International journal of pharma sciences and Research;5(4):163-70.

3. Valeria C Sandrim, Ana CT. Palei, Ingrid et al. Nitric Oxide Formation Is Inversely Related to Serum Levels of Antiangiogenic Factors Soluble Fms-Like Tyrosine Kinase-1 and Soluble Endogline in Preeclampsia. Hypertension. $\mathrm{J}$ of the American Heart Association, 2008;52:402-7.

4. Chwalisz K, Buhimschi I, Garfield RE. Role of nitric oxide in obstetrics. Prenat Neonat Med 1996;1:292-328.

5. Kumar A, Ghosh B K, Murthy N S. Maternal thyroid hormonal status in preeclampsia. Indian J Med Sci 2005;59:57-63.

6. Ides M Colin, Peter Kopp, Jakob Zbaren. Expression of nitric oxide synthase 3 in human thyroid follicular cells. Evidence for increased expression in hyperthyroidism. European J of Endocrinology 1997;136:649-55.

7. Suchanda Sahu, Mary Daniel, Rebecca, Study of uric acid and nitric oxide concentrations in preeclampsia and pregnancy. International J of Biological and Medical Research 2011;2:390-3.
8. Silver RK ,Kupfermine M J , Russell T L et al., Evaluation of nitric oxide as a mediator of severe preeclampsia . Am J Obstet Gynecol 1996;175:1013-7.

9. Hudicek Martincic G, Kusan Jukic M et al. Nitric oxidean important signaling molecule in normal and pathological pregnancy. Lijec Vjesn. 2004;126(3- 4):805.

10. Henry M Kronenberg, Shlomo Melmed. Pregnancy Hypertension. Textbook of William's Obstetrics, 23rd edition. Chapter 34:p 706.

11. Jie Sun, Xueji Zhang, Mark Broderick, Harry Fein. Measurement of Nitric Oxide Production in Biological Systems by Using Griess Reaction Assay. Sensors 2003;3:276-84.

12. Muraleedharan N, Janardhanan JS. Thyroid hormone status in preeclampsia patients: A case- control study. Muller J Med Sci Res 2017;8:68-73.

13. Ghasemi, Zahediasi. Reference values of serum nitric oxide in an adult population. Clin. Biochem 2010;43(12):89-94.

14. ACOG Committee on Obstetric Practice. ACOG practice bulletin. Diagnosis and management of preeclampsia and eclampsia. Number 33, January 2002. American College of Obstetricians and Gynecologists. Int J Gynaecol Obstet. 2002;77:67-75.

15. Lana K Wagner. Diagnosis and management of preeclampsia and eclampsia. Am Fam Physician 2004;70(12):2317-24.

16. Valeria C. Sandrim, Ana C T Palei, Ingrid F Metzger, Valeria A Gomes, Ricardo C Cavalli, Jose E TanusSantos. Nitric Oxide Formation Is Inversely Related to Serum Levels of Antiangiogenic Factors Soluble Fms Like Tyrosine Kinase - 1 and Serum Endogline in Preeclampsia. Hypertension. 2008;52:402-7.

17. Jong Weon Choi, Moon WhanIm, Soo Hwan Pai., Nitric Oxide Production Increases during Normal Pregnancy and Decreases in Preeclampsia. Annals of Clinical \& Laboratory Science 2002;32:3.

18. Ahmet Vara, Yasemin Yildirimb, Ece Onura N., Endothelial dysfunction in preeclampsia; Increased Homocysteine and decreased Nitric Oxide Levels. Gynecol Obstet Invest 2003;56:221-4.

19. Maul H, Longo M, Saade GR, Garfield RE. Nitric oxide and its role during pregnancy: from ovulation to delivery. Curr Pharm Des. 2003;9(5):359- 80.

20. Hudicek Martincic G, Kusan Jukic M et al. Nitric oxidean important signaling molecule in normal and pathological pregnancy. Lijec Vjesn. 2004;126(3- 4):805.

21. Lyall et al. Nitric oxide concentrations are increased in the fetoplacental circulation in preeclampsia. Am. J.Obstet. Gynecol. 1995;173,714-8.

22. Silver et al. Evaluation of nitric oxide as a mediator of severe preeclampsia. Am. J. Obstet. Gynecol. 1996;175,1013-7.

23. Boccardoet al. Systemic and fetal maternal nitric oxide synthesis in normal pregnancy and pre-eclampsia. Br. J. Obstet. Gynaecol. 1996;103,879-86.

24. McAllister RM et al. Thyroid status and nitric oxide in rat arterial vessels. J Endocrinol. 2005;185(1):111-9.

25. Rodríguez et al. Undetectable levels of tumor necrosis factor- $\alpha$, nitric oxide and inadequate expression of inducible nitric oxide synthase in congenital hypothyroidism. European Cytokine Network 2003; 14(1):65-8. 